\title{
Roux-en-Y hepaticojejunostomy: An evaluation of its indications and results in benign and malignant biliary tree disease
}

\author{
Tamang TY', Maharjan DK², Thapa PB ${ }^{3}$ \\ 'Tseten Yonjen Tamang, Lecturer; ${ }^{2}$ Dhiresh Kumar Maharjan, Lecturer; ${ }^{3}$ Prabin Bikram Thapa, Associate Professor, \\ Department of Surgery, Kathmandu Medical College Teaching Hospital, Kathmandu, Nepal.
}

\begin{abstract}
Background: Roux-en-Y Hepaticojejunostomy (RYHJ) is the most common form of reconstruction of the biliary pathway. It is a time honoured, durable, less resource intensive and a definitive procedure.

Objectives: The aim of this study was to evaluate the indications of Hepaticojejunostomy and to assess the outcome of surgery following change in surgical technique of Hepaticojejunostomy.

Methods: All patients who underwent RYHJ from Magh 2067 (January 2011) till Ashad 2071 (July 2014) in a single surgical unit at the Department of Surgery, Kathmandu Medical College Teaching Hospital were included. Demographics of the patient, indications for surgery, type of surgery, hospital stay and duration of drain placement were evaluated. Since, this is a prospective descriptive study, only mean value was calculated for age, hospital stay and duration of drain placement using SPSS Statistics 17.0 for statistical analysis.

Results: Twenty patients underwent RYHJ during the study period. Fifteen percent $(n=3)$ were done for malignant diseases. The most common indication was choledocholithiasis $(n=8,40 \%)$ followed by choledochal cyst $(n=3,15 \%)$ and bile duct injury $(n=3,15 \%)$. The morbidity was minimal. The mean duration of drain in situ was four days (range one to 14 days) and the mean hospital stay was six days (range two to 15 days). Prolonged drain placement and hospital stay was noted in two patients with malignant diseases. However, they were non bilious in nature. We encountered no mortality. Conclusion: Roux-en-Y Hepaticojejunostomy (RYHJ) is a common and safe method of biliary reconstruction. The indication of the procedure is varied and wide.
\end{abstract}

Key words: Choledochal cyst, Choledocholithiasis, Roux-en-Y Hepaticojejunostomy (RYHJ)

\section{INTRODUCTION}

$\mathrm{R}$ oux-en-Y Hepaticojejunostomy (RYHJ) is a common procedure. With high success rates reported early in the century ${ }^{1-4}$ and continued legacy of its safety, it is the most common form of reconstruction of the biliary pathway. The indication of the procedure has been varied and wide'. With the advancement of interventional radiology (e.g. transhepatic stenting), endoscopic procedure (e.g. ERCP stenting) and popularity of other bilioenteric anastomosis such as choledochoduodenostomy, cholecystoduodenostomy, hepaticoduodenostomy (HD), choledochocholedochal anastomosis, the use of RYHJ has been challenged.

Address for correspondence

Dr. Tseten Yonjen Tamang

Fellow Hepatobiliary and Liver Transplantation

Lecturer, Department of Surgery, Kathmandu Medical College

Teaching Hospital, Kathmandu, Nepal

E-mail: tsetenyonjen@gmail.com
However, it continues to be a time honoured, durable, less resource intensive and a definitive procedure ${ }^{1}$. It is likely to be more commonly practiced. Refinement of the surgical technique of RYHJ has enhanced its popularity further. We evaluated our patients who underwent RYHJ for various indications. Our aim was to evaluate the indications of RYHJ and to assess the outcome of surgery following change in surgical technique of RYHJ.

\section{METHODS}

All patients who underwent RYHJ from Magh 2067 (January 2011) till Ashad 2071 (July 2014) in a single surgical unit at the Department of surgery, Kathmandu Medical College Teaching Hospital were prospectively included in our study. The data collected included age, gender, indications for surgery, type of surgery, hospital stay and duration of drain placement. Since, this is a prospective descriptive study, only mean value was calculated for age, hospital stay and duration of 
drain placement using SPSS Statistics 17.0 for statistical analysis. For homogeneity, we excluded all RYHJs done as a part of a Whipples procedure. Ethical clearance and informed consent from the patients were taken.

All patients underwent CECT (triphasic) abdomen or MRCP preoperatively for evaluation of the biliary anatomy. Surgical technique has evolved. In this series, surgical steps included adequate exposure of the porta. A well vascularized, roux-en- $Y$, mucosa to mucosa, tension free RYHJ was done. The roux en $Y$ limb was transected at $30-35 \mathrm{~cm}$ from the ligament of Treitz. Monofilament small size suture (5-0 PDS) was used under loupe magnification (X2.5). Abdominal drains were placed at the discretion of the operating surgeon. All patients were managed postoperatively with IV fluids, analgesics and antibiotics. Early ambulation and per oral nutrition (POD-1) was initiated for all.

\section{RESULTS}

Twenty patients underwent RYHJ during Magh 2067 (January 2011) till Ashad 2071 (July 2014) in a single surgical unit at the Department of Surgery, Kathmandu Medical College Teaching Hospital. There were nine males (45\%) and 11 females (55\%). The mean age of the patients was 50 years. The age ranged from 22 to 73 years. The indications of RYHJ were varied but mostly consisted of benign diseases ( $85 \%, n=17$ ) (Figure 1). Fifteen percent $(n=3)$ were done for malignant diseases.
The most common indication was choledocholithiasis $(n=8,40 \%)$ followed by choledochal cyst $(n=3,15 \%)$ and bile duct injury $(n=3,15 \%)$. Choledocholithiasis required a biliary reconstruction due to presence of associated conditions such as choledochoduodenal fistula or choledochocele or because it was a primary choledocholithiasis (Table 1).

The mean hospital stay was six days (range 2-15 days) (Figure 2). Hospital stay was longest for patients with malignant diseases. An elderly patient with hilar cholangiocarcinoma had a prolonged stay (14 days) due to associated medical comorbidity. The other patient with prolonged hospital stay had cystic duct carcinoma. She recovered well from her surgery except for prolonged non bilious drain output. She stayed in the hospital due to logistical reasons (resident of rural area).

Abdominal drain were not kept for $20 \%(n=4)$ of patients (Figure 3). There were no incidences of bile leak in any of our patients (with or without abdominal drain). In those who had abdominal drains, the mean duration of drain in situ was four days, ranging from one to fourteen days. Prolonged drain placement was noted in two patients with malignant diseases. However, they were non bilious in nature. One patient was discharged with abdominal drain in situ. Her drain was removed in her follow up. Hence, RYHJ is indicated in various conditions. The morbidity is minimal. We encountered no mortality.

\section{Table 1: All indications of Hepaticojejunostomy in the study group.}

\begin{tabular}{ll}
\hline \multicolumn{1}{|c}{ Benign diseases } & Malignant diseases \\
\hline Choledocholithiasis With Choledochocele & $\begin{array}{l}\text { Incidental Carcinoma Gall Bladder (In Situ) With Positive Cystic } \\
\text { Duct Margin }\end{array}$ \\
\hline $\begin{array}{l}\text { Choledocholithiasis, CHD Calculi, Chronic Calculus } \\
\text { Cholecystitis With Cholecystocholedochal Fistula }\end{array}$ & Hilarcholangiocarcinoma \\
\hline Choledocholithiasis - Primary & Cystic Duct Carcinoma \\
\hline Choledocholithiasis - Primary & \\
\hline Choledochal Cyst & \\
\hline Post Cholecystectomy Status With Distal CBD Stricture & \\
\hline Choledocholithiasis - Primary & \\
\hline Post Cholecystectomy Biliary Stricture, Bismuth Type II & \\
\hline Choledocholithiasis - Primary & \\
\hline Hepaticolithiasis With Cholelithiasis & \\
\hline Choledocholithiasis & \\
\hline Bile Duct Injury & \\
\hline Choledochal Cyst & \\
\hline Choledochal Cyst & \\
\hline Chronic Calculus Cholecystitis/ Mirrizzi & \\
\hline Choledocholithiasis With Benign CBD Growth & \\
\hline Hepaticolithiasis, CBD Calculi With Cholecystoduoneal Fistula & \\
\hline
\end{tabular}




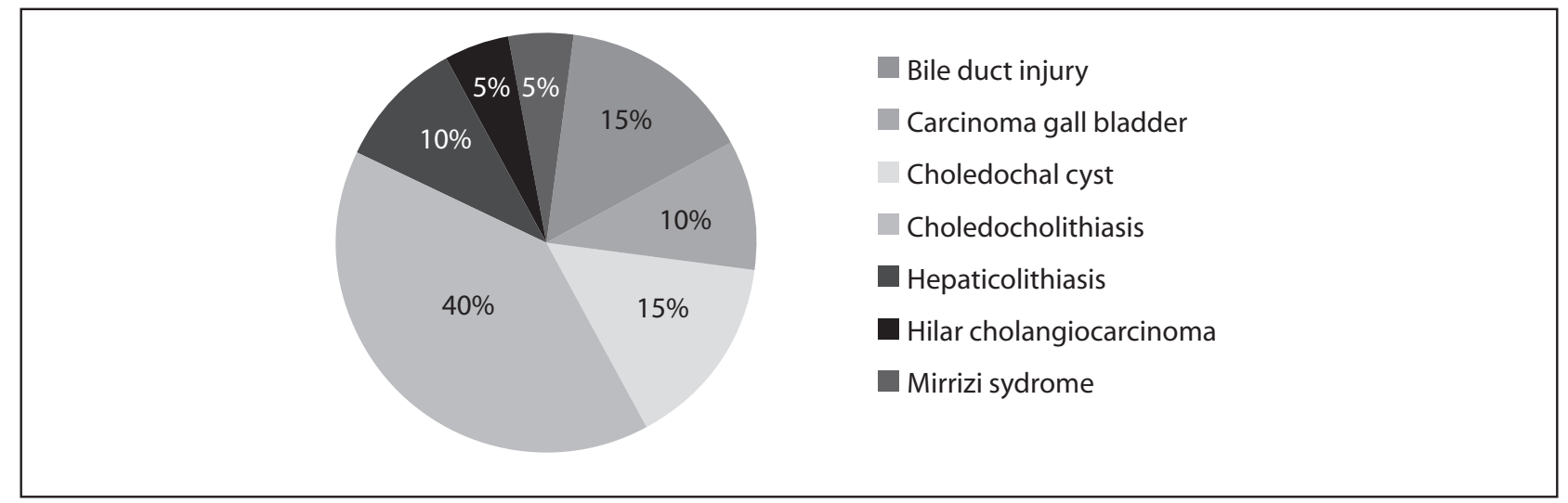

Figure 1: Indications for Hepaticojejunostomy

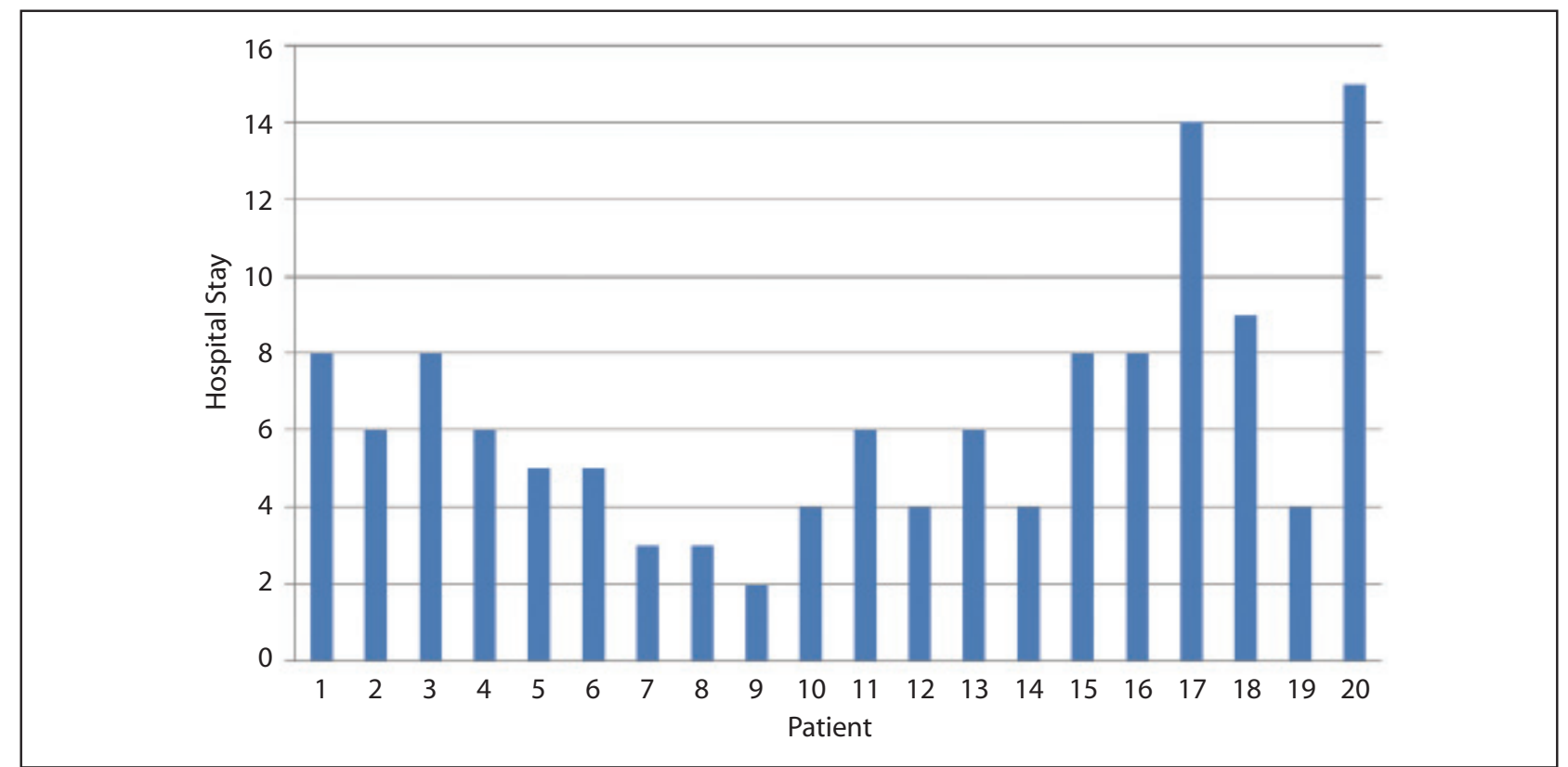

Figure 2: Duration of hospital stay (days) among the patients.

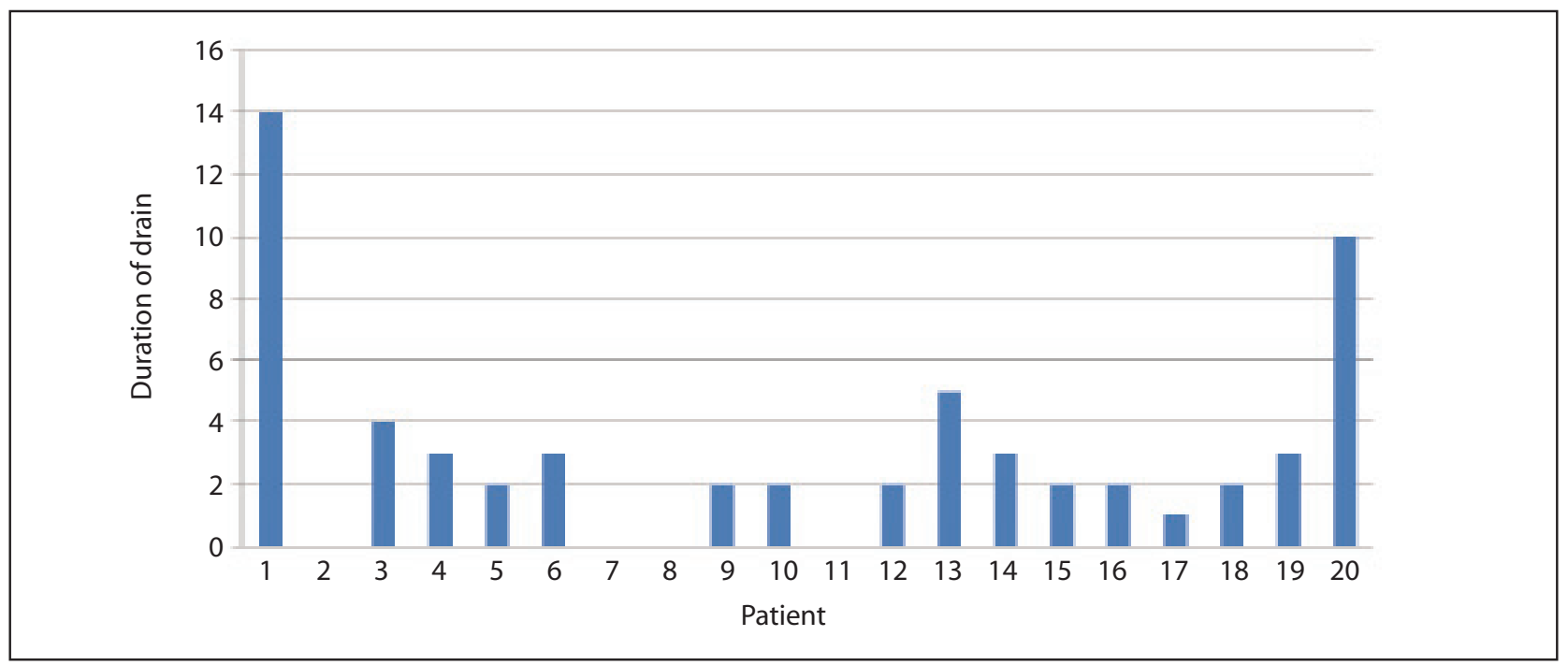

Figure 3: Duration of drain placement (days) among the patients. 


\section{DISCUSSION}

Roux-en-Y Hepaticojejunostomy (RYHJ) is a common procedure. Despite the advancement of interventional radiology (e.g. transhepatic stenting), endoscopic procedure (e.g. ERCP stenting), and popularity of other bilioenteric anastomosis such as choledochoduodenostomy, cholecystoduodenostomy, hepaticoduodenostomy (HD), choledochocholedochal anastomosis; RYHJ is the most common form of management of the pathology of biliary tree. RYHJ removes the diseased bile duct and allows a well vascularized biliary and enteric stoma for anastomosis. Unlike duodenum, the use of a jejunum allows a tension free anastomosis ${ }^{1,}$ with the least incidence of biliary reflux and stricture formation.

In the literature, RYHJ has been done for varied benign diseases such as bile duct injury (BDI), biliary fibrosis due to chronic pancreatitis, penetrating trauma of the porta hepatis, previous bilioenteric anastomosis with subsequent stricture formation, choledochal cyst, other causes of iatrogenic biliary trauma such as gastrectomy, pancreatic and hepatic resection, portal decompressive procedures and liver transplantation'. Malignant diseases for which RYHJ has been done include cholangiocarcinoma, carcinoma gall bladder infiltrating the common bile duct or hepatic ducts'.

During our study period 20 RYHJs were done. Most $\mathrm{RYHJ}$ were done for benign diseases. The most common indication for RYHJ in our study was choledocholithiasis. It is traditional to perform RYHJ in presence of primary calculi, markedly dilated CBD $(>2 \mathrm{~cm})$, stricture or stenosis of the distal bile duct or inability to remove all stones from the duct ${ }^{5}$. In our study, choledocholithiasis was associated with cholecystoduodenal fistula, choledochocele or were primary calculi. RYHJ for primary choledocholithiasis still remains a controversy. Some authors such as Girard et $\mathrm{al}^{6}$ who reported 69 patients with retained and recurrent bile duct stones, did not perform RYHJ.

We performed RYHJ for three Choledochal cyst, which is described as the treatment of choice for type I, IV and selected type $\mathrm{V}$ choledochal cyst $^{7-9}$. The excision of the extrahepatic cyst is essential and the biliary continuity is best corrected with a RYHJ5. Shimotakahara et al compared RYHJ to hepaticoduodenostomy (HD) after the excision of choledochal cyst and found superior results with $\mathrm{RYHJ}^{10}$. The complications including endoscopy proven bilious gastritis, cholangitis and adhesive bowel obsrtuction were higher after HD (42\%) compared to $7.1 \%$ after $\mathrm{RYHJ}^{10}$.
There were three bile duct injury (BDI) in our study for which RYHJ was done. RYHJ is the recommended method of reconstruction of biliary path (Blumgart) after BDI (Strasberg Type E) ${ }^{11}$. Results of repair of BDI is influenced by various factors such as type of BDI, associated sepsis and comorbidities. Though RYHJ is the recommended method, some authors have reported better results with end to end ductal anastomosis ${ }^{12}$ and others with hepaticoduodenostomy ${ }^{13}$.

We performed two RYHJs for hepaticolithiasis. Many authors advocate RYHJ as an important step in the management of hepaticolithiasis ${ }^{14-16}$ though, mostly literature is controversial. Li SQ et $\mathrm{al}^{17}$ observed higher rate of retained stones and cholangitis in their patients with RYHJ than compared to choledochotomy and T-tube placement and suggested selective use of RYHJ. They advocate RYHJ when hepaticolithiasis is associated with complicated extrahepatic ducts or secondary branch stricture, congenital bile duct stricture and dysfunction of the papilla of vater. Liver resection is done in the presence of liver atrophy, intrahepatic biliary stenosis or unilobular severe liver fibrosis ${ }^{14}$. Herman et $\mathrm{al}^{14}$ performed liver resection in 41 patients with hepaticolithiasis and observed good long term results with liver resection alone than when associated with RYHJ ( $p=0.0006)$. Complications included cholangitis, recurrent stones and liver abscess. However, we performed RYHJ alone in our patients and observed no complications. Appropriate selection of patients with hepaticolithiasis for RYHJ is perhaps important.

LuCBetal ${ }^{18}$ reported good results with RYHJin sixpatients with Bismuth type II hilar cholangiocarcinoma. Our experience was similar with hilar cholangiocarcinoma. The indication of RYHJ in Carcinoma of the gall bladder includes cystic duct margin positivity. Performing RYHJ, allows a $\mathrm{R}^{0}$ resection ${ }^{5,19}$. We met with two such cases for which RYHJ was successfully performed.

RYHJ continues to be a time honoured and durable procedure and is likely to be more commonly practiced $^{20-22}$. High success rates $(>90 \%$ with long term follow up) were reported early in the century ${ }^{1-4}$. Initially, the indications were restricted, due to high operative mortality and difficult surgical technique'. Wider and successful use of RYHJ may be credited to sound knowledge of the biliary anatomy (MRCP/ ERCP), meticulous surgical technique and improved postoperative care ${ }^{1}$.

Previously, surgical technique of RYHJ included, use of two layer anastomosis, and inappropriate length of 
roux loop. Refinement of surgical technique including adequate exposure, healthy well vascularized biliary stump, retrocolic, tension free, mucosa to mucosa RYHJ using non absorbable sutures (PDS) and an adequate length of the roux loop has improved the perioperative morbidity and mortality. Though traditionally, 50-70 $\mathrm{cm}$ roux loop is constructed, recent evidences report feasibility of short roux limb $(20 \mathrm{~cm})$. A short limb allows easier performance of endoscopic biliary intervention when indicated ${ }^{23}$.

Our study also confirms the safety of the procedure. In our study, drains were generally removed by day four of surgery and in $20 \%$ of patients, no drain were placed intraoperatively. We did not have any incidence of reinsertion of abdominal drain. The hospital stay and duration of drain placement were comparable to most other studies ${ }^{24}$. Anastomotic stricture has been reported by some authors ${ }^{5}$. Some have attributed it to roux loop and some to the consequence of the primary disease. We will require a long term follow up to assess the occurrence of anastomotic stricture. Peptic ulceration was previously reported in $7-13 \%$ of patients ${ }^{20,21}$. It has been attributed to gastric hypersecretion and absence of neutralization of gastric juices following $\mathrm{RYH} \mathrm{J}^{22}$. The occurrence of peptic ulcer has greatly reduced due to better postoperative management with proton pump inhibitors. Complications such as cholangitis, bile leak, biliary fistula, biliary peritonitis and recurrent cholangitis and retained stone in calculous diseases have also been reported.

Rothlin et al reported a postoperative complication rate of $33 \%$, late complication rate of $25 \%$ in 51 patients who underwent RYHJ for benign diseases of the bile duct ${ }^{25}$. Pappalarado et al reported a postoperative mortality of $4.6 \%$ and morbidity of $13 \%{ }^{22}$. Stefanni $P$ et a ${ }^{26}$ reported a mortality rate of $3.7-6.6 \%$. The operative mortality has been on the decline. In our own series, there was no mortality. Despite the literature suggesting such complications, we did not witness any in our patients. It may be due to our small study population and long term results are yet to be seen. Hence, RYHJ is a surgical procedure with varied indications and good results.

\section{CONCLUSION}

Roux-en-Y Hepaticojejunostomy is a common and safe method of biliary reconstruction. The indication of the procedure has been varied and wide. Refinement of the surgical technique of RYHJ has decreased its morbidity and mortality.

\section{REFERNCES}

1. Sarmiento JM. Hepaticojejunostomy: Indications and Surgical Technique. Operative Techniques in General Surgery. 2000 Dec;2(4):295-303.

2. Stewart L, Way LW. Bile duct injuries during Laparoscopic Cholecystectomy. Arch Surg. 1995 Oct;130(10):1123-9.

3. Murr MM, Gigot JF, Nagorney DM, Harmsen WS, Ilstrup DM, Farnell MB. Long-term results of Biliary Reconstruction after Laparoscopic Bile Duct Injuries. Arch Surg. 1999 Jun;134(6):604-10.

4. Lillemoe KD, Martin SA, Cameron JL, Yeo CJ, Talamini MS, Kaushal S, et al. Major Bile Duct Injuries during Laparoscopic Cholecystectomy: Follow-up after combined radiological and surgical management. Ann Surg. 1997 May;225(5):459-68.

5. Blumgart LH. Surgery of the liver, biliary tract and pancreas. 4th ed. Philadelphia: Saunders Elsevier; 2006.

6. Girard RM, Legros G. Retained and recurrent bile duct stones. Surgical or nonsurgical removal? Ann Surg. 1981 Mar;199(2):21-7.

7. Mercadier M, Chigot JP, Clot JP, Langlois P, Lansioux P. Caroli's disease. World J Surg 1984 Feb;8(1):22-9.

8. Nagorney DM, Mcllrath DC, Adson MA. Choledochal cyst in adults: clinical management. Surgery. 1984 Oct;96(4):656-63.

9. Todani T, Watanabe $\mathrm{Y}$, Narusue $\mathrm{M}$, Tabuchi K, Okajima K. Congenital bile duct cysts: classifications, operative procedures, and review of thirty seven cases including cancer arising from choledochal cysts. Am J Surg. 1977 Aug;134(2):263-9.

10. Shimotakahara A, Yamataka A, Yanai T, Kobayashi $H$, Okazaki T, Lane GJ, Miyano T. Roux en $Y$ hepaticojejunostomy or hepaticoduodenostomy for biliary reconstruction during the surgical treatment of choledochal cyst: which is better? Pediatr Surg Int. 2005 Sep;21:5-7.

11. Hajjar NA, Tomus C, Mocan L, Mocan T, Graur F, lancu C, Zaharie F. Management of bile duct injuries following laparoscopic cholecystectomy: Long term outcome and risk factors influencing biliary reconstruction. Chirurgia. 2014 Jul-Aug;109:493-9.

12. Jablonska B, Lampe P, Olakowski M, Gorka Z, Lekstan A, Gruzska T. Hepaticojejunostomy vs. End to end biliary reconstruction in the treatment of iatrogenic bile duct injury. J Gastrointest Surg. 2009 Mar;13:1084-93. 
13. Moraca RJ, Lee FT, Ryan JA, Traverso W. Long term biliary function after reconstruction of major bile duct injuries with hepaticoduodenostomy or hepaticojejunostomy. Arch Surg. 2002 Aug;137(8):889-94.

14. Herman P, Pernini MV, Pugliese V, Pereira JC, Machado MA, Saad WA, et al. Does bilioenteric anastomosis impair results of liver resection in primary intrahepaticlithiasis? World J Gastroenterol. 2010 Jul;16(27):3423-6.

15. Pekmezci S, Saribeyoglu K, Aytac E, Serdar B. Hepaticojejunostomy with the "Hand Fan" technique. Hepatobiliary Pancreat Dis Int. 2013 Apr;12(2):210-4.

16. Stefanni P, Carboni M, Patrassi N, Basoli A, de Bernardinis G, Negro P. Roux-en-Y Hepaticojejunostomy: A Reappraisal of its Indications and Results. Ann Surg. 1975 Feb;181(2):213-9.

17. Li SQ, Liang L, Peng BG, Lai JM, Lu MD, Li DM. Hepaticojejunostomy for hepatolithiasis: A critical appraisal. World J Gastroenterol. 2006 Jul;12(26):4170-4.

18. Lu CB, Ren PT. Treatment of hilar cholangiocarcinoma of Bismuth-Corlette type III with hepaticojejunostomy. Wspolczesna Onkol. 2013;17(3):298-301.

19. Shimizu $Y$, Ohtsuka $M$, Ito $H$, Kimura F, Shimizu $H$, Togawa A, et al. Should the extrahepatic bile duct be resected for locally advanced gallbladder cancer? Surgery. 2004 Nov; 136(5):1012-7.

20. Bismuth H, Franco D, Corlette MB, Hepp J. Long term results of Roux en $\mathrm{Y}$ hepaticojejunostomy. Surg Gynecol Obstet. 1978 Feb;136(2):161-7.

21. Lane CE, Sawyers JL, Riddell DH, Scott HW. Long term results of Roux-en-Y hepatocholangiojejunostomy. Ann Surg. 1973;177:714-22.

22. Pappalardo G, Correnti S, Mobarhan S, Trentino $\mathrm{P}$, Pietropaolo A, Frattaroli $\mathrm{F}$, et al. Long term results of roux en $Y$ hepaticojejunostomy and hepaticojejunoduodenostomy. Ann Surg. 1982 Aug;196(2):149-52.

23. Felder SI, Menon VG, Nissen NN, Margulies DR, Lo S, Colguhoun SD. Hepaticojejunostomy using shortlimb Roux en $Y$ reconstruction. JAMA Surg. 2013 Mar;148(3):253-7.

24. Koh YX, Chiow AKH, Chok AY, Lee LS, Tan SS, Ibrahim S. Recurrent pyogenic cholangitis: Disease characteristics and patterns of recurrence. ISRN Surgery 2013, Article ID 536081, 9 pages. Doi: http:// dx.doi.org/10.1155/2013/536081

25. Rothlin MA, Lopfe $M$, Schlumpf R, Largieder F. Long term results of hepaticojejunostomy for benign lesions of the bile ducts. Am J Surg. 1998 Jan;175(1):22-6.

26. Stefanni $P$, Carboni $M$, Patrassi N, Basoli A, de Bernardinis G, Negro P. Roux-en-Y Hepaticojejunostomy: A Reappraisal of its Indications and Results. Ann Surg. 1975 Feb;181(2):213-9. 